\title{
Zinc Vacancy - Hydrogen Complexes as Major Defects in ZnO Nanowires Grown by Chemical Bath Deposition
}

José Villafuerte, ${ }^{1,2}$ Fabrice Donatini, ${ }^{2}$ Joseph Kioseoglou, ${ }^{3}$ Eirini Sarigiannidou, ${ }^{1}$ Odette ChaixPluchery, ${ }^{1}$ Julien Pernot, ${ }^{2}$ and Vincent Consonni ${ }^{*}$

${ }^{1}$ Univ. Grenoble Alpes, CNRS, Grenoble INP, LMGP, F-38000 Grenoble, France

${ }^{2}$ Univ. Grenoble Alpes, CNRS, Grenoble INP, Institut NEEL, F-38000 Grenoble, France

${ }^{3}$ Physics Department, Aristotle University of Thessaloniki, 54124 Thessaloniki, Greece

\section{*Corresponding Author:}

Vincent Consonni

LMGP, Grenoble INP - Minatec, 3 parvis Louis Néel - CS 50257 - 38016 Grenoble cedex 1

Tel : (+33) 456529358

vincent.consonni@grenoble-inp.fr 


\section{ABSTRACT}

Crystal defects in unintentionally doped $\mathrm{ZnO}$ nanowires grown by chemical bath deposition (CBD) play a capital role on their optical and electrical properties, governing the performances of many nanoscale engineering devices. However, the nature of these crystal defects is still highly debated. In particular, the hydrogen-related defects have not been explored in detail yet although the growth medium operates in aqueous solution. By using four-point probe resistivity measurements, we show that $\mathrm{ZnO}$ nanowires grown by $\mathrm{CBD}$ using zinc nitrate and hexamethylenetetramine exhibit a high electrical conductivity with electron densities ranging from $2.7 \times 10^{18}$ to $3.1 \times 10^{19} \mathrm{~cm}^{-3}$. Most of them have a metallic electrical conduction. By combining density-functional theory calculations with cathodoluminescence and Raman spectroscopy, we reveal that the high electrical conductivity mostly originates from the formation of interstitial hydrogen in bond-centered sites $\left(\mathrm{H}_{\mathrm{BC}}\right)$ and of zinc vacancy - hydrogen $\left(V_{\mathrm{Zn}}-n \mathrm{H}\right)$ complexes. In particular, the $\mathrm{HBC}_{\mathrm{BC}}$ and $\left(V_{\mathrm{Zn}-3 \mathrm{H}}\right)$ complex are found to act as two shallow donors with a very low formation energy, for which the most stable configurations are reported. Additionally, this combined theoretical and experimental approach allows us to revisit the highly debated origin of the visible and ultra-violet emission bands in the luminescence spectra. They are found to be mostly related to $V_{\mathrm{Zn}}$ and $\left(V_{\mathrm{Zn}}-n \mathrm{H}\right)$ complexes located in the bulk and on the surfaces of $\mathrm{ZnO}$ nanowires. These findings represent an important step forward in the identification of the predominant native and extrinsic defects driving the electronic structure properties of $\mathrm{ZnO}$ nanowires grown by $\mathrm{CBD}$. They further reveal the significance of hydrogen engineering to tune the source of crystal defects for optimizing the physical properties of $\mathrm{ZnO}$ nanowires. 


\section{INTRODUCTION}

$\mathrm{ZnO}$ nanowires (NWs) are of high interest as building blocks in a vast number of nanoscale devices. ${ }^{1-5}$ As a low-cost, low-temperature and easily implemented process, ${ }^{6}$ chemical bath deposition (CBD) represents the most widely used technique to form $\mathrm{ZnO}$ NWs with a broad range of morphology using the spontaneous/selective area growth approaches on unpatterned/patterned $\mathrm{ZnO}$ seed layers, respectively. ${ }^{7}$ Until now, most of the efforts have been dedicated to optimizing the structural properties of ZnO NWs grown by CBD, specifically their dimensions (i.e. diameter, length), arrangement, and verticality. ${ }^{8-10}$ In contrast, the nature of intrinsic/extrinsic point defects in the center of unintentionally doped $\mathrm{ZnO}$ NWs grown by $\mathrm{CBD}$ along with their correlated optical/electrical properties are still controversial, to a large extent, despite its primary importance. A couple of investigations of the electrical properties of unintentionally doped $\mathrm{ZnO}$ NWs grown by $\mathrm{CBD}$ have shown that their electrical conductivity is typically high with an expected electron density lying in the range of $5 \times 10^{17}$ to $1.5 \times 10^{19} \mathrm{~cm}^{-}$ ${ }^{3} \cdot{ }^{11-15}$ This high electron density indicates the incorporation and formation of a high density of intrinsic/extrinsic point defects in their center, which should carefully be identified and mastered.

The nature of intrinsic/extrinsic point defects governing the electronic structure properties of $\mathrm{ZnO}$ in its form of single crystals and epitaxial films has been highly debated over the last two decades. ${ }^{16-17}$ The oxygen vacancy $\left(V_{0}\right)$ with its low formation energy over a broad range of Fermi level has been identified, in the past, as one of the major intrinsic point defects. A consensus has however emerged progressively on the fact that $V_{O}$ acts as a deep donor and thus it cannot account for the high electron density in unintentionally doped $\mathrm{ZnO}{ }^{18-26}$ The zinc vacancy $\left(V_{\mathrm{Zn}}\right)$ with its low formation energy when the Fermi level is close to the conduction band minimum (CBM) has been shown to be formed as well, but it acts as a deep acceptor and thus it cannot explain the source of n-type conductivity in unintentionally doped $\mathrm{ZnO}$ either. ${ }^{20-}$ 
${ }^{21}$ Instead, the predominance of hydrogen-related defects has been more and more emphasized by using density-functional theory (DFT) calculations from the pioneered work of Van de Walle, showing that hydrogen exhibits a unique positive charge state over the expected range of Fermi level in $\mathrm{ZnO}^{27}$ Hydrogen can be incorporated in $\mathrm{ZnO}$ in the form of interstitial hydrogen $\left(\mathrm{H}_{\mathrm{i}}\right),{ }^{27}$ substitutional hydrogen on the oxygen lattice site $\left(\mathrm{Ho}_{\mathrm{O}}\right){ }^{28}$ as well as zinc vacancy - hydrogen $\left(V_{\mathrm{Zn}}-n \mathrm{H}\right)$ defect complexes where $n$ is the number of involved $\mathrm{H}_{\mathrm{i}}$ atoms and typically lies in the range of 1-4. ${ }^{29-30}$ The presence of hydrogen in $\mathrm{ZnO}$ has been experimentally proved by electron paramagnetic resonance (EPR) and electron nuclear double resonance (ENDOR) spectroscopy, ${ }^{31-32}$ infrared absorption spectroscopy, ${ }^{33-34}$ photoluminescence, ${ }^{34-36}$ and Raman spectroscopy. ${ }^{34}$ While $\mathrm{H}_{\mathrm{i}}$ in the bond-centered site (i.e. $\mathrm{H}_{\mathrm{BC}}$ ) has been identified as the most stable configuration, the vast number of configurations related to $(V \mathrm{Zn}-n \mathrm{H})$ defect complexes is a complex issue that still needs to be clarified. In particular, the expected number of involved $\mathrm{H}_{\mathrm{i}}$ atoms in that defect complex has not been completely identified yet. Several reports have contradictorily shown from DFT calculations that $\left(V_{\mathrm{Zn}}-2 \mathrm{H}\right)$ or $\left(V_{\mathrm{Zn}-3 \mathrm{H}}\right)$ could be the most stable defect complexes. ${ }^{21,29-30,37-39}$

More importantly, the electronic structure properties of unintentionally doped $\mathrm{ZnO} \mathrm{NWs}$ grown by CBD have mostly been related to the formation of single vacancies including $V_{\mathrm{O}}$ and $V_{\mathrm{Zn}}{ }^{40-41}$ However, no direct correlation has thoroughly been achieved with hydrogen although the growth medium is full of hydrogen atoms in the form of water molecules and hydroxide ions. Numerous investigations have shown the effects of post-deposition treatments under hydrogen atmosphere or plasma on the properties of $\mathrm{ZnO}$ NWs grown by CBD to passivate $V_{O}$ and $V_{Z n}$ and likely form $\left(V_{\mathrm{Zn}}-n \mathrm{H}\right)$ defect complexes as well as to increase their electrical conductivity. ${ }^{42-47}$ These investigations have suggested that a hydrogen incorporation may occur during their growth by CBD. Huang et al. revealed the presence of hydrogen in ZnO NWs grown by CBD using nuclear magnetic resonance. ${ }^{48}$ Urgessa et al. identified the predominance 
of the $I_{4}$ line assigned to $\mathrm{Ho}_{\mathrm{O}}$ in the near-band edge (NBE) emission of the photoluminescence spectra of $\mathrm{ZnO}$ NWs grown by $\mathrm{CBD}$ and investigated their stability as a function of annealing temperature.$^{49}$ Barbagiovanni et al. measured the presence of hydrogen in $\mathrm{ZnO}$ NWs grown by CBD by using elastic recoil detection analysis, but they excluded the significant role of hydrogen-related defects in their optical properties. ${ }^{50}$ Later on, Cossuet et al. revealed that the high electrical conductivity of polarity-controlled vertical $\mathrm{ZnO}$ nanorods grown by CBD using the selective area growth approach is due to the massive incorporation of hydrogen. ${ }^{14}$ This was additionally found to be dependent upon their O- or Zn-polarity: O- and Zn-polar ZnO nanorods were shown to exhibit the predominant $\mathrm{I}_{4}$ and $\mathrm{I}_{5}$ lines assigned to $\mathrm{Ho}_{0}$ and $(V \mathrm{Zn}-n \mathrm{H})$ with an unknown $n$, respectively. However, no experimental data were shown in the most widely used spontaneous growth approach using a polycrystalline $\mathrm{ZnO}$ seed layer that typically results in the formation of $\mathrm{ZnO} \mathrm{NWs}$ with a much smaller diameter. No theoretical data were reported either to identify the most stable configurations of hydrogen-related defects.

In the present article, we combine four-point probe and low-temperature cathodoluminescence measurements collected on single $\mathrm{ZnO}$ NWs grown by $\mathrm{CBD}$, as well as Raman spectroscopy with DFT calculations to unambiguously show the major role of hydrogen in their electronic structure properties. The most stable configurations of hydrogen-related defects in $\mathrm{ZnO} \mathrm{NWs}$ are identified with care by coupling theoretical and experimental data, opening the way for tuning their electronic structure properties and thus their optical/electrical properties as an important requirement for improving the performances of the related nanoscale devices. The origin of the visible and ultra-violet emission bands in the luminescence spectra is also revisited and mainly related to $V_{\mathrm{Zn}}$ and $\left(V_{\mathrm{Zn}}-n \mathrm{H}\right)$ defect complexes.

\section{METHODS}

2.1. Synthesis of $\mathrm{ZnO}$ nanowires. The synthesis of $\mathrm{ZnO}$ NWs was performed following a double-step process. First, the polycrystalline $\mathrm{ZnO}$ seed layers were deposited by dip coating 
on $\mathrm{Si}(100)$ substrates pre-cleaned with acetone and isopropyl alcohol in an ultrasonic bath. A solution containing $375 \mathrm{mM}$ of zinc acetate dihydrate $\left(\mathrm{Zn}\left(\mathrm{CH}_{3} \mathrm{COO}\right)_{2} .2 \mathrm{H}_{2} \mathrm{O}\right.$, Sigma-Aldrich) and $375 \mathrm{mM}$ of monoethanolamine (MEA, Sigma-Aldrich) in pure ethanol was initially stirred for several hours at $60{ }^{\circ} \mathrm{C}$ on a hot plate and then at room temperature. The substrates were subsequently dipped in the solution under a controlled atmosphere $(<15 \%$ hygrometry $)$ and annealed for $10 \mathrm{~min}$ at $300^{\circ} \mathrm{C}$ on a hot plate and for $1 \mathrm{~h}$ at $500{ }^{\circ} \mathrm{C}$ in an oven under air. Second, ZnO NWs were grown by CBD in a sealed reactor containing an aqueous solution of zinc nitrate hexahydrate $\left(\mathrm{Zn}\left(\mathrm{NO}_{3}\right)_{2} \cdot 6 \mathrm{H}_{2} \mathrm{O}\right.$, Sigma-Aldrich) and hexamethylenetetramine (HMTA, SigmaAldrich) mixed in an equimolar ratio of $30 \mathrm{mM}$ and placed for $5 \mathrm{~h}$ in an oven kept at $85{ }^{\circ} \mathrm{C}$ corresponding to a $\mathrm{pH}$ value around 5.5.

2.2. Characterization techniques. The morphological properties of $\mathrm{ZnO}$ NWs were investigated with a FEI Quanta 250 field-effect scanning electron microscopy (FESEM) instrument. $5 \mathrm{~K}$ cathodoluminescence measurements of $\mathrm{ZnO}$ NWs were performed with a FEI Inspect F50 FESEM equipped with a liquid helium-cooled stage. The cathodoluminescence signal was collected through a parabolic mirror and analyzed with a $550 \mathrm{~mm}$ focal length monochromator equipped with 600 grooves/mm diffraction grating. Cathodoluminescence spectra were recorded with a thermoelectric cooled silicon CCD detector using the low acceleration voltage of $5 \mathrm{kV}$ and small spot size (i.e., less than $10 \mathrm{~nm}$ ). Raman spectroscopy was performed by using a Horiba/Jobin Yvon Labram spectrometer equipped with a liquid nitrogen-cooled CCD detector. The $514.5 \mathrm{~nm}$ line of an $\mathrm{Ar}^{+}$laser with a power on the sample surface close to $0.64 \mathrm{~mW}$ was focused to a spot size close to $1 \mu \mathrm{m}^{2}$ using a 50 times long working distance objective. The integration time was dependent upon the spectral region and ranged from $2 \mathrm{~min}$ for low wavenumbers to $1 \mathrm{~h}$ for the hydrogen-related phonon modes. The spectra were calibrated using a silicon reference sample at room temperature by fixing the theoretical position of the silicon Raman line to $520.7 \mathrm{~cm}^{-1}$. The four-terminal single $\mathrm{ZnO} \mathrm{NW}$ 
devices with ohmic contacts using $\mathrm{Ti} / \mathrm{Au}(50 \mathrm{~nm} / 50 \mathrm{~nm})$ were fabricated using a Leo 1530 SEM equipped with a RAITH Elphy electron beam lithography (EBL) system and a PLASSYS e-beam deposition chamber. The electrical access was provided by four-probe nanomanipulators located in a FEI Inspect F50 FESEM instrument using a Keithley 2636B sourcemeter.

2.3. Density-functional theory method. The investigation of the wurtzite structure of $\mathrm{ZnO}$ and of the corresponding point defects was performed using the VASP code with projector augmented-wave (PAW) potentials ${ }^{51-52}$ under the Perdew-Burke-Ernzerh derivation of the generalized gradient approximation $(\mathrm{GGA}-\mathrm{PBE})^{53-54}$ of the DFT. The reciprocal-space resolution for $k$-point mesh generation was set by a Monkhorst-Pack mesh of $8 \times 8 \times 6$ for the $1 \mathrm{x} 1 \mathrm{x} 1$ unit cell, while the $k$-point mesh was $\Gamma$-centred and the cut-off energy was set to $600 \mathrm{eV}$. In the present investigation, a 4x4x3 supercell consisting of 192 atoms was considered, while convergence with respect to $k$-point sampling, slab and vacuum thickness was explicitly checked. Extensive tests concluded that smaller cells or multiple defects in the $4 \times 4 \times 3$ supercell are insufficient for the structural relaxation and the accurate calculations of the optoelectronic properties of point defects in $\mathrm{ZnO}$. Reliable optical properties require an accurate determination of the electronic structure of the band gap. Hence, the DFT $+U$ method was used in order to accurately calculate the electronic structure properties and consequently the optical properties. Initially, $U$ was incorporated only for the $d$-states of $\mathrm{Zn}$ and the $U_{d, Z n}$ was set to 7.5 following Ref. 55, a parameter value that produces good lattice constants, and significantly improves the bandgap energy of $\mathrm{ZnO}$ from $0.70 \mathrm{eV}$ (GGA-PBE) to $1.85 \mathrm{eV}$. Nevertheless, it has been evidenced in Ref. 56 that the correct band gap energy of $3.4 \mathrm{eV}$ for $\mathrm{ZnO}$ can be obtained, if in addition to the $U$ values for the $d$-states, $U$ values are considered also for the $s$-or $p$-states. The corresponding $U$ values were obtained from R.M. Sheetz et al. $.^{57} U_{\mathrm{d}, \mathrm{Zn}}=10.5 \mathrm{eV}, U_{\mathrm{s}, \mathrm{Zn}}=0 \mathrm{eV}$, and $U_{\mathrm{p}, \mathrm{O}}=7.0 \mathrm{eV}$. In principles, the values of oxygen chemical potential $\mu \mathrm{o}$ lie in the range of - 
4.22 (i.e. formation enthalpy of $\mathrm{ZnO}$ ) to $0 \mathrm{eV}$. In the present calculations, $\mu$ o was set to -2.11 $\mathrm{eV}$, corresponding to intermediate growth conditions (i.e. in the middle of $\mathrm{O}$ - and $\mathrm{Zn}$-rich conditions). The formation energies were calculated using the well-established formalisms described in Ref. 16. The formation energy of a complex point defect $(D)$ in a charge state $(q)$ depends on the growth conditions and on the influence of the environment expressed by the chemical potentials $\mu$ through the equation:

$$
E^{f}\left(D^{q}\right)=E_{\text {tot }}\left(D^{q}\right)-E_{\text {tot }}(\text { bulk })-\sum_{i} n_{i} \mu_{i}+q\left(E_{F}+E_{V B M}\right)+E_{c o r r}
$$

where $E_{\text {tot }}\left(D^{q}\right)$ is the total energy of a supercell containing a single defect $D^{q}$ in charge state $q$, and $E_{\text {tot }}\left(\right.$ bulk) is the total energy of a perfect equivalent supercell. $n_{i}$ represents the number of either host or impurity atoms of type $i$, which was added $\left(+n_{i}\right)$ to or removed $\left(-n_{i}\right)$ from the supercell in order to form the complex point defect $D . \mu_{i}$ represents the chemical potentials of the corresponding species of type $i$. The Fermi level $E_{F}$ was considered with respect to the energy of the valence band maximum (VBM) $E_{V B M}$ of the perfect crystal, which was further corrected by aligning the average electrostatic potential in the perfect crystal and a bulk-like area of the defected supercell. The correction term $E_{\text {corr }}$ was considered with respect to the finite k-point sampling and/or elastic, electrostatic interactions between the defected supercells as described in detail in Refs. 58-60.

\section{RESULTS}

3.1. Morphological properties of $\mathrm{ZnO}$ nanowires. The growth of unintentionally doped $\mathrm{ZnO}$ NWs by $\mathrm{CBD}$ was achieved under standard conditions on a $c$-axis oriented polycrystalline $\mathrm{ZnO}$ seed layer deposited by dip coating on silicon. ${ }^{61} \mathrm{~A}$ sealed reactor containing an equimolar mix of zinc nitrate hexahydrate and hexamethylenetetramine (HMTA) in aqueous solution was placed in a regular oven for $5 \mathrm{~h}$ at $85{ }^{\circ} \mathrm{C}$, corresponding to a $\mathrm{pH}$ value around $5.5 .^{62}$ The morphology of ZnO NWs is presented in Figure 1, showing the formation of vertically aligned 
nano-objects that preferentially nucleate on the $\mathrm{ZnO}$ nanoparticles with the semi-polar and polar orientations in the seed layer. ${ }^{63}$ The typical mean diameter and length of $\mathrm{ZnO}$ NWs are of 100 $\pm 27 \mathrm{~nm}$ and $1560 \pm 71 \mathrm{~nm}$, respectively.

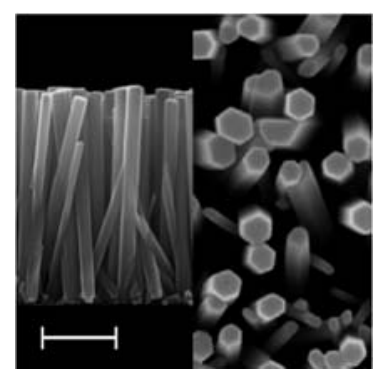

Figure 1. Cross-sectional- and top-view FESEM images of $\mathrm{ZnO}$ NWs grown by CBD under standard conditions using the spontaneous growth approach. The scale bar corresponds to 500 $\mathrm{nm}$ and $250 \mathrm{~nm}$ for the cross-sectional view and top-view images, respectively.

3.2. Electrical properties of $\mathrm{ZnO}$ nanowires. To investigate their electrical properties, several $\mathrm{ZnO}$ NWs were dispersed on dedicated silicon wafers covered with a $100 \mathrm{~nm}$-thick $\mathrm{SiO}_{2}$ layer grown by thermal oxidation for their processing. The ohmic contacts using $\mathrm{Ti} / \mathrm{Au}(50 \mathrm{~nm}$ / $50 \mathrm{~nm}$ ) metallization were fabricated by EBL. The electrical measurements were subsequently recorded in patterned metal contact configuration. The four-point manipulator probes in a FEI Inspect F50 FESEM instrument were placed on the EBL patterned $\mathrm{Ti} / \mathrm{Au}$ local ohmic contacts. The current varying in the range of a few microamperes was injected from the outer contacts while the voltage was measured across the two inner contacts separated by a length $l$, as shown in the inset of Figure 2a. The resistance $R$ of each $\mathrm{ZnO} \mathrm{NW}$ between the two inner contacts was deduced from the slope of the I-V linear curve, as revealed in Figure 2a. A special emphasis was made to fix the range of electron beam dose used to desorb the oxygen species adsorbed on the NW surfaces, which are responsible for the carrier depletion leading to the huge apparent resistance of the NW. ${ }^{64}$ The evolution of the resistance as a function of the electron beam dose is presented in Figure S1. A value of $1 \times 10^{5} \mu \mathrm{C} / \mathrm{cm}^{2}$ was used for the electron beam dose before the resistance measurement of each NW, which was further taken 
once the current vs time was stable to avoid any persistent conductivity. ${ }^{65-66}$ A statistical analysis of the four-probe resistance $R$ over the length $l$ as a function of the NW radius $r$ was achieved over a population of six $\mathrm{ZnO}$ NWs, as presented in Figure $\mathbf{2 b}$, along with experimental data reported on unintentionally doped $\mathrm{ZnO}$ NWs grown by carbothermal reduction, ${ }^{12}$ metal-organic chemical vapour deposition (MOCVD),${ }^{65}$ hydrothermal method, ${ }^{12}$ and CBD. ${ }^{14}$
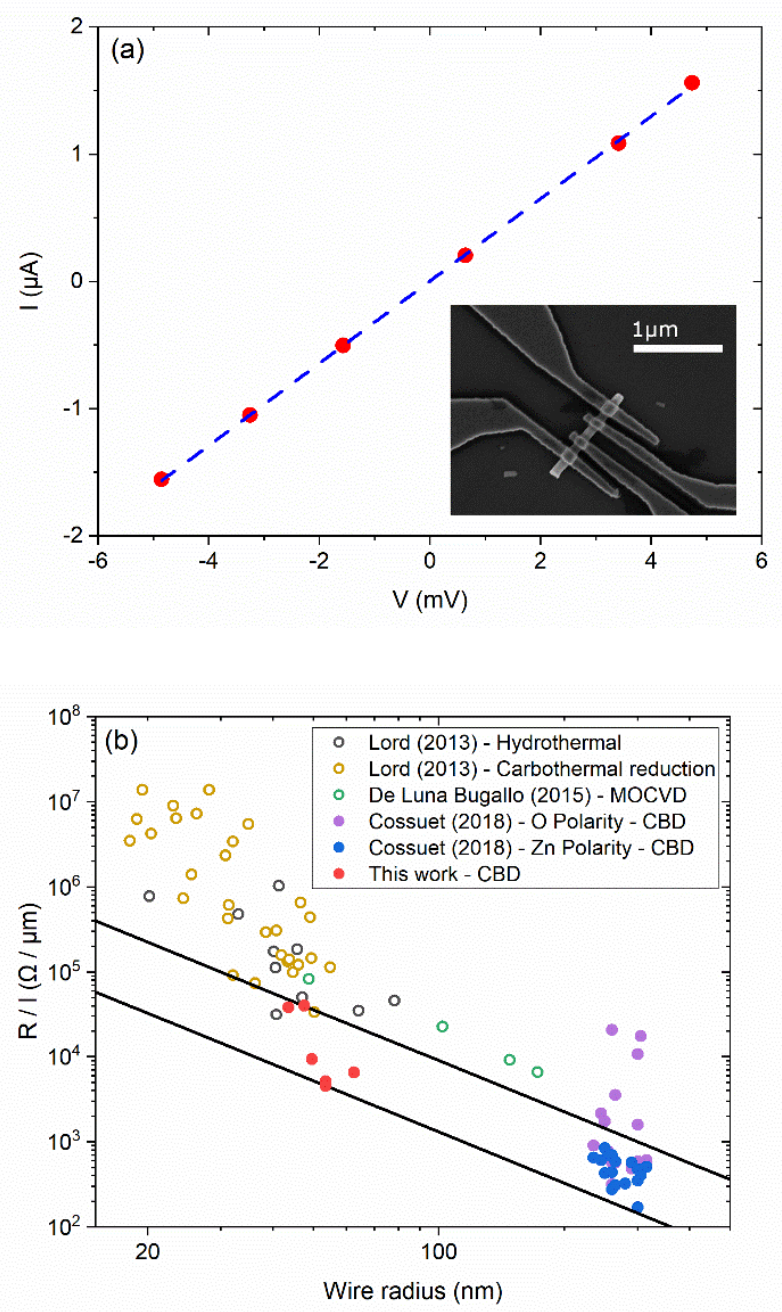

Figure 2. (a) Current-voltage (I-V) measurement using a four-point probe configuration on a single $\mathrm{ZnO} \mathrm{NW}$ grown by $\mathrm{CBD}$ under standard conditions using the spontaneous growth approach. The inset is a top-view FESEM image of the single NW device in patterned metal contact configuration. The current is injected from the two outer contacts and the voltage drop is measured from the two inner contacts. (b) $R / l$ versus $r$ along with experimental data reported 
on unintentionally doped $\mathrm{ZnO}$ NWs grown by carbothermal reduction, ${ }^{12} \mathrm{MOCVD},{ }^{65}$ hydrothermal method, ${ }^{12}$ and CBD. ${ }^{14}$

The $\mathrm{ZnO} N W s$ exhibit $R / l$ values varying in the range of $4.6 \times 10^{3}$ to $4.0 \times 10^{4} \Omega / \mu \mathrm{m}$ with their radius $r$ ranging from 43.5 to $62.5 \mathrm{~nm}$. The electrical resistivity $\rho$ is written as $R S / l$, in which $S$ represents the conduction section. In the range of radius considered, a bulk-like conduction dominated by the core of the NW is expected and hence $S$ is given by $S_{v o l}=\pi r^{2}$ in a flat-band regime. The present experimental data together with the one reported in Ref. 14 on unintentionally doped $\mathrm{Zn}$-polar $\mathrm{ZnO}$ nanorods grown by $\mathrm{CBD}$ under identical conditions using the selective area growth approach are delimited in Figure $\mathbf{2 b}$ by $1 / r^{2}$ dependences corresponding to a bulk-like conduction. Following this procedure, the mean electrical resistivity of $\mathrm{ZnO} N W \mathrm{~s}$ is found to be in the range of $4.1-28.4 \mathrm{~m} \Omega \mathrm{cm}$, corresponding to a high electrical conductivity of $35.2-243.1 \mathrm{~S} / \mathrm{cm}$. It is further deduced that the single ZnO NWs measured electrically in the present investigation very likely exhibit the $\mathrm{Zn}$-polarity. ${ }^{14} \mathrm{By}$ assuming that the electron mobility in ZnO NWs varies from 50 to $80 \mathrm{~cm}^{2} / \mathrm{Vs}$ as typically reported from field-effect transistor (FET) measurements, ${ }^{67-68}$ the carrier density lies in the range of $2.7 \times 10^{18}$ to $3.1 \times 10^{19} \mathrm{~cm}^{-3}$. Additional FET measurements of these NWs revealed no channel conduction modulation versus backgate bias voltage up to $-50 \mathrm{~V}$. For higher backgate bias voltage, the $\mathrm{SiO}_{2}$ layer breakdown occurred. By considering that the NW radius is about $50 \mathrm{~nm}$ and that the capacitance is overestimated by a factor of $2.5,{ }^{69}$ this shows that the carrier density is above $2.6 \times 10^{18} \mathrm{~cm}^{-3}$. This confirms that the lowest value of the carrier density in the deduced range is very close to the effective critical concentration $n_{C}$ of $4.2 \times 10^{18} \mathrm{~cm}^{-3}$ corresponding to the Mott transition separating the non-metal/insulator from metal regimes in terms of electrical conduction. ${ }^{70}$ Most of these NWs thus exhibit a metallic electrical conduction. This high electron density in unintentionally doped ZnO NWs grown by CBD cannot be explained by the only role of single vacancies including $V_{\mathrm{O}}$ nor by the incorporation 
of residual extrinsic impurities including aluminum, gallium or indium because i) no metal additives were used here and because ii) the range of $\mathrm{pH}$ below 7 in the present standard conditions is associated with unfavorable electrostatic repulsions between the possible residual metal cations and positively charged surfaces of $\mathrm{ZnO}$ NWs. ${ }^{71-72}$ Instead, it should be noted that the crystallization process of $\mathrm{ZnO}$ NWs by CBD typically occurs through the dehydration process of $\left[\mathrm{Zn}\left(\mathrm{H}_{2} \mathrm{O}\right)_{6}\right]^{2+}$ ions, as shown by x-ray absorption near-edge structure measurements in Ref. 73 and by the modeling of the NW elongation process in Refs. 74-75. This crystallization process is highly favorable for the massive incorporation of hydrogen in the center of $\mathrm{ZnO}$ NWs. Additionally, the chemical precursors contain carbon and nitrogen, which may play a role as well.

3.3. Structure of crystal defects using density-functional theory. In order to investigate in more details the role of hydrogen in $\mathrm{ZnO}$, we performed DFT calculations using the VASP code with PAW potentials ${ }^{51-52}$ under the GGA-PBE. ${ }^{53-54}$ A 4x4x3 supercell consisting of 192 atoms was considered for thoroughly investigating the wurtzite structure of $\mathrm{ZnO}$ and the corresponding point defects. The DFT $+U$ method was used in order to accurately calculate the electronic structure properties and consequently the optical properties with $U$ values taken for the $s$ - and $d$-states of $\mathrm{Zn}$ atoms as well as for the $p$-states of $\mathrm{O}$ atoms from R.M. Sheetz et al.. ${ }^{57}$ $U_{\mathrm{d}, \mathrm{Zn}}=10.5 \mathrm{eV}, U_{\mathrm{s}, \mathrm{Zn}}=0 \mathrm{eV}$, and $U_{\mathrm{p}, \mathrm{O}}=7.0 \mathrm{eV}$. In the present calculations, $\mu \mathrm{o}$ was set to -2.11 $\mathrm{eV}$, corresponding to intermediate growth conditions (i.e. in the middle of O- and Zn-rich conditions). The formation energies were calculated using the well-established formalisms described in Ref. 16. The formation energies of $V_{\mathrm{Zn}}$ and $\left(V_{\mathrm{Zn}}-n \mathrm{H}\right)$ defect complexes with $n=1$ 4 as a function of the Fermi level are presented in Figure 3a. The transition levels of the different thermodynamic charge states of $V_{\mathrm{Zn}}$ and $\left(V_{\mathrm{Zn}}-n \mathrm{H}\right)$ defect complexes are summarized in Figure 3b. 

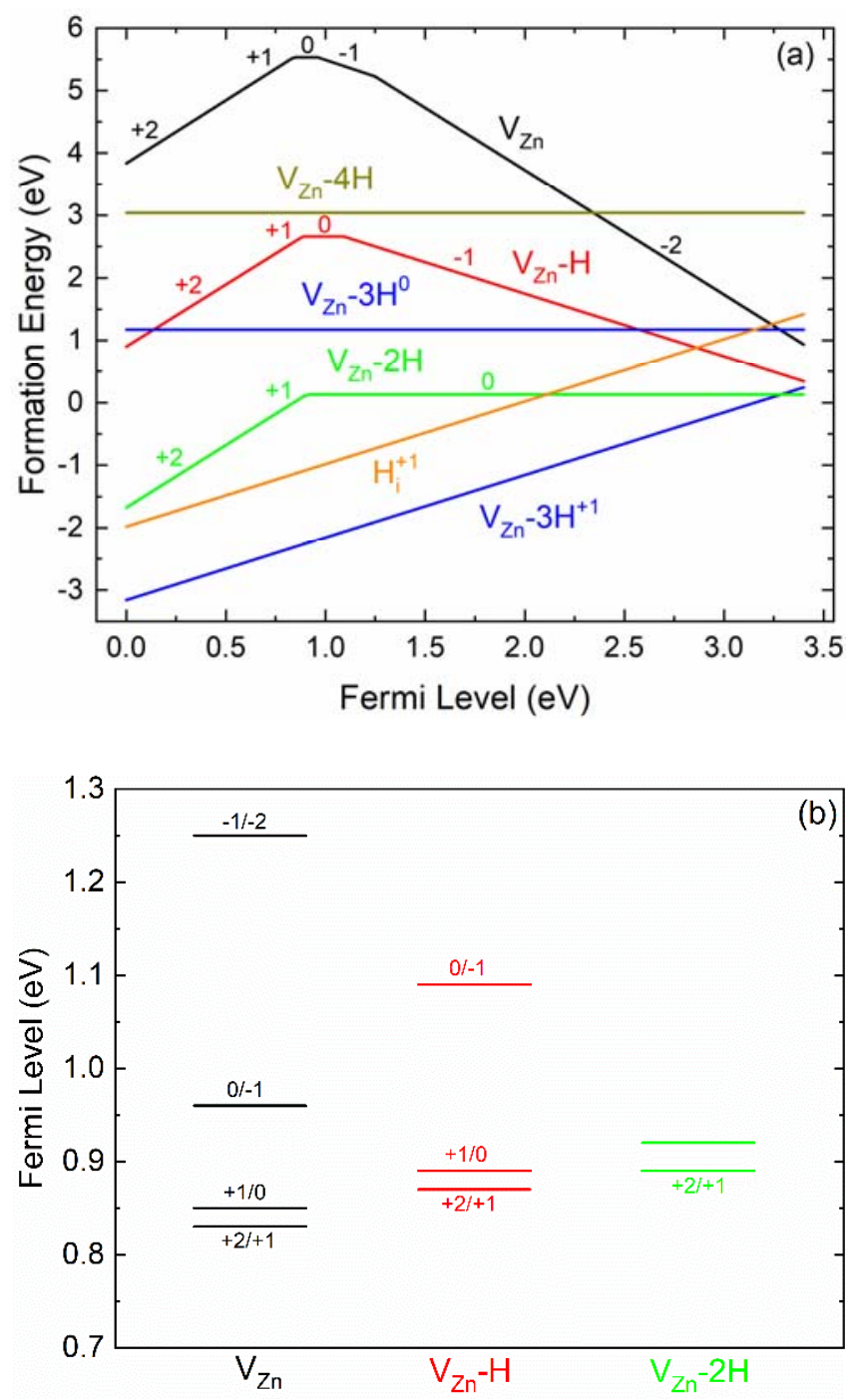

Figure 3. (a) Formation energies of hydrogen-related defects in $\mathrm{ZnO}$ as a function of the Fermi level, obtained from DFT calculations. For each charge state, only the most stable configuration with the lowest energy is presented. The zero of Fermi energy was chosen at the VBM. Chemical potential values of $\mu_{\mathrm{O}}=-2.11 \mathrm{eV}$ and $\mu_{\mathrm{H}}=-0.475 \mathrm{eV}$ were used. (b) Transition levels of each of $V_{\mathrm{Zn}},\left(V_{\mathrm{Zn}}-\mathrm{H}\right),\left(V_{\mathrm{Zn}}-2 \mathrm{H}\right)$ defect as a function of the vertically aligned Fermi level.

As expected from previous investigations reporting DFT calculations, ${ }^{16-17} V_{\mathrm{Zn}}$ is a deep acceptor with a -2 charge state and low formation energy when the Fermi level is close to the CBM. In contrast, $\mathrm{H}_{\mathrm{BC}}$ with the +1 charge state is a shallow donor with a very low formation energy regardless of the Fermi level in the bandgap, which is in agreement with Refs. 27-28. The situation of $\left(V_{\mathrm{Zn}}-n \mathrm{H}\right)$ defect complexes strongly depends on the number $n$ of involved $\mathrm{H}_{\mathrm{i}}$ 
atoms. The $\left(V_{\mathrm{Zn}}-\mathrm{H}\right)$ complex is a deep acceptor with a -1 charge state and fairly low formation energy when the Fermi level is close to the CBM. It is thus unlikely to be ionized at room temperature. In contrast, the $(V \mathrm{Zn}-2 \mathrm{H})$ complex is neutral and exhibits a low formation energy over a broad range of Fermi level. Both defect complexes are liable to form in $\mathrm{ZnO}$, but their electrical activity is low at room temperature. In contrast, it is shown that the $\left(V_{\mathrm{Zn}}-3 \mathrm{H}\right)$ complex is a shallow donor with a +1 charge state that exhibits a very low formation energy regardless of the Fermi level in the bandgap, suggesting a massive formation in $\mathrm{ZnO}$ along with a large electrical activity. In contrast, the $\left(V_{\mathrm{Zn}}-4 \mathrm{H}\right)$ complex with a neutral charge state exhibits a fairly high formation energy regardless of the Fermi level in the bandgap and thus is not expected to play a significant role here. All the atomic configurations of the $\left(V_{\mathrm{Zn}}-n \mathrm{H}\right)$ defect complexes in the tetrahedral environment of the relaxed wurtzite structure were calculated and the most stable ones are represented in Figure 4. It should be noticed that in order to investigate the hydrogen incorporation at the position of a $V \mathrm{Zn}$, two inequivalent positions of $\mathrm{H}$ atoms should be considered. The axial position where an $\mathrm{H}$ atom saturates the axial oxygen atom and three equivalent basal positions where an $\mathrm{H}$ atom is bonded to the basal oxygen atom can be defined. The calculations concluded that for an odd number of $\mathrm{H}$ atoms $\left(\right.$ i.e. $\left(V_{\mathrm{Zn}}-\mathrm{H}\right)$ and $\left.\left(V_{\mathrm{Zn}}-3 \mathrm{H}\right)\right)$, one $\mathrm{H}$ atom is systematically bonded to the axial position. Only by the use of a single electron addition $\left(\right.$ i.e. $\left.\left(V_{\mathrm{Zn}}-\mathrm{H}\right)^{-1}\right)$ or for the cases of even number of $\mathrm{H}$ atoms $\left(\right.$ i.e. $\left.\left(V_{\mathrm{Zn}}-2 \mathrm{H}\right)\right)$, the basal positions are preferential. These basal positions of the $\mathrm{H}$ atoms in $V \mathrm{Zn}$ with the presence of an axial $\mathrm{O}$ dangling bond have already been identified experimentally. ${ }^{76-77}$ The corresponding electronic band structures are given in Figure S2. Eventually, the present DFT calculations show that $\mathrm{H}_{\mathrm{BC}}$ and $\left(\mathrm{V}_{\mathrm{Zn}}-3 \mathrm{H}\right)$ defect complex are both shallow donors, which should be considered as the major source of n-type conductivity in $\mathrm{ZnO}$ grown in a hydrogen-rich medium along with Ho. 


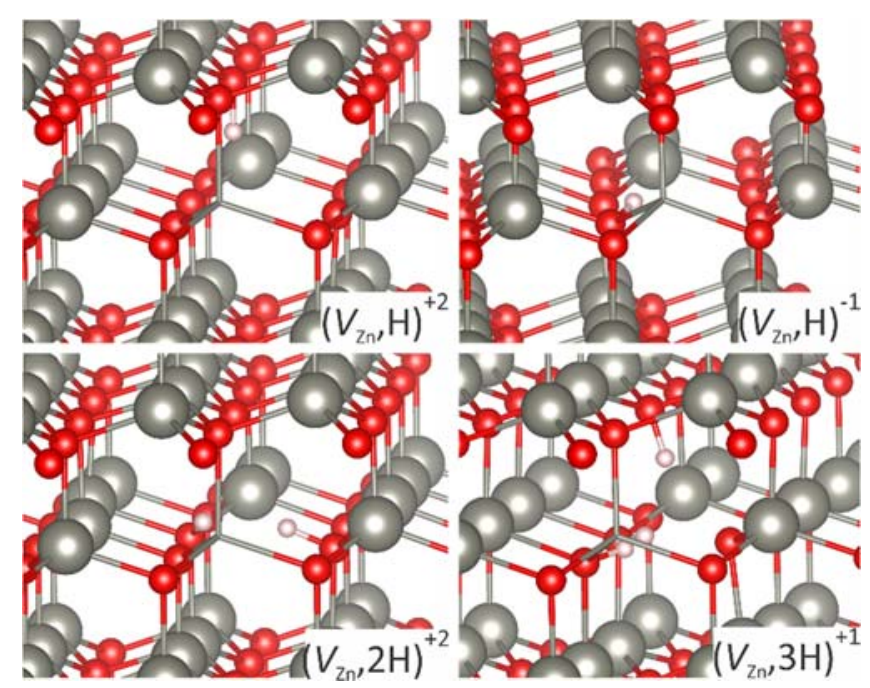

Figure 4. Structural models for the most stable atomic configurations of each of $\left(V_{\mathrm{Zn}-\mathrm{H}}\right),\left(V_{\mathrm{Zn}}-\right.$ $2 \mathrm{H})$, and $\left(V_{\mathrm{Zn}}-3 \mathrm{H}\right)$ defect complex. Large grey balls denote $\mathrm{Zn}$ atoms, small red balls denote oxygen atoms and small white balls denote hydrogen atoms. The $\mathrm{Zn}$ atom in front of the $V \mathrm{Zn}$ was removed for the sake of clarity and only its bonds with the neighboring oxygen atoms are presented.

\subsection{Cathodoluminescence spectra and their assignment to crystal defects using}

density-functional theory. In order to correlate these theoretical data with experimental data, cathodoluminescence measurements collected on the ZnO NWs grown by CBD under standard conditions using the spontaneous growth approach were achieved at low temperature. A typical spatially-resolved 5K cathodoluminescence spectrum is presented in Figure 5a, along with a zoom-in in the NBE in Figure $5 \mathbf{b}$. 

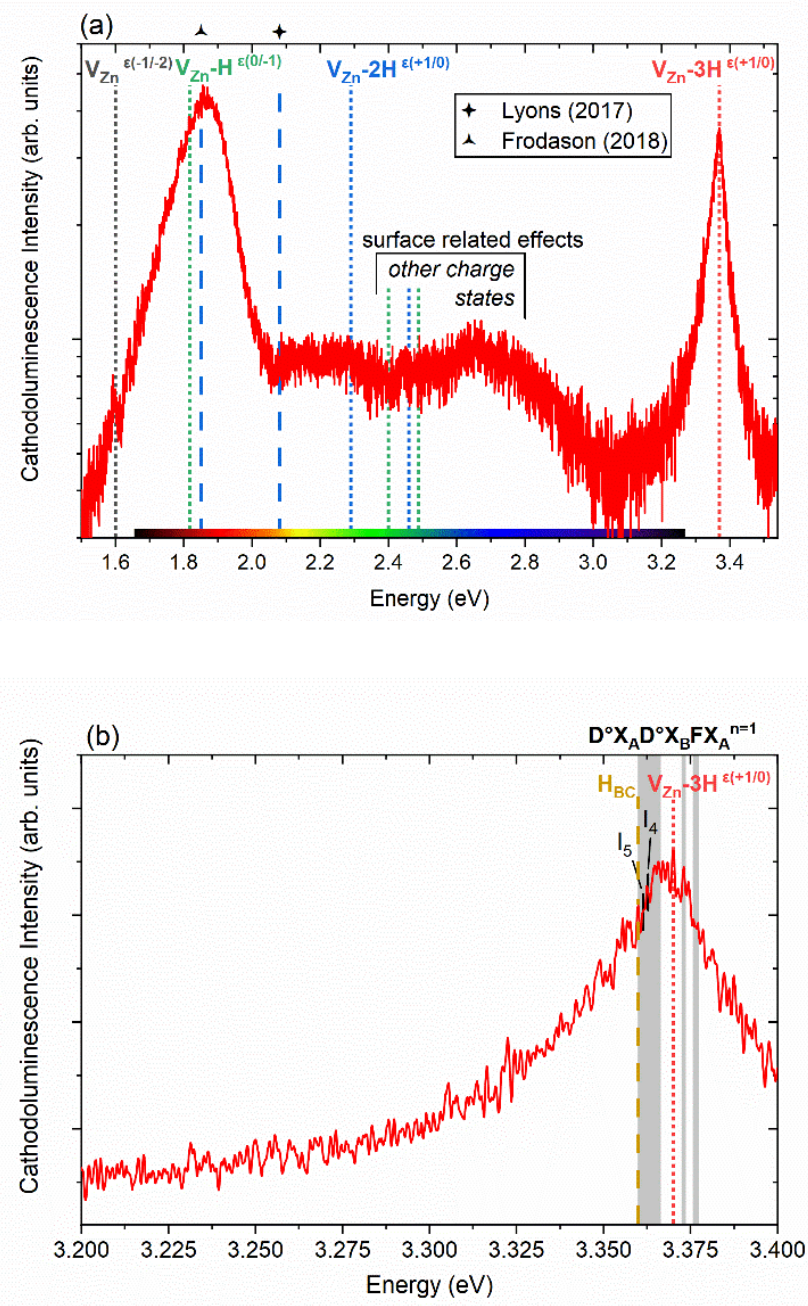

Figure 5. (a) Typical 5K cathodoluminescence spectrum of unintentionally doped $\mathrm{ZnO}$ NWs grown by CBD under standard conditions using the spontaneous growth approach. The insets represent the emission energy of transitions as inferred from DFT calculations in this work and in Refs. 21, 39. (b) Corresponding NBE emission region. The insets represent the emission energy of transitions as inferred from DFT calculations in this work and from experimental data in Refs. 34, 36.

The NBE emission is dominated by radiative transitions involving neutral donor-bound Aexcitons pointed at $3.36 \mathrm{eV}$. From the $I$ nomenclature used to label the excitonic lines, ${ }^{35}$ the shape and position of the NBE emission may be attributed to the occurrence of the $I_{4}$ and $I_{5}$ lines at 3.3628 and $3.3614 \mathrm{eV}$ related to $\mathrm{Ho}_{0}$ and $\left(V_{\mathrm{Zn}-\mathrm{nH})}\right)$ defect complexes with an unknown $n$, respectively. ${ }^{34,36}$ The line assigned to $\mathrm{H}_{\mathrm{BC}}$ around $3.360 \mathrm{eV}$ is also involved. ${ }^{34}$ The visible 
emission band is marked by the highly intense red-orange band centered at $1.86 \mathrm{eV}$ and by the less intense yellow/green band centered at $2.25 \mathrm{eV}$ along with a green/blue band centered at $2.65 \mathrm{eV}$. Although $V_{\mathrm{O}}$ has been related to the yellow/green emission band ${ }^{78}$ of $\mathrm{ZnO}$ NWs grown by $\mathrm{CBD}^{79-82}$ and of $\mathrm{ZnO}$ nanocrystals, ${ }^{83-84}$ it should be noted here that its role has recently been questioned by DFT calculations. ${ }^{21}$ The related emission energies corresponding to the $(+1 / 0)$ and $(+2 /+1)$ transitions levels were shown to be smaller than $1 \mathrm{eV}$ and thus do not lie in the range of energy probed in the cathodoluminescence spectra. In the present case, it is worth noticing that $\mathrm{Zn}(\mathrm{II})$ species are the limiting reactants in the $\mathrm{CBD}$ of $\mathrm{ZnO} N W s .{ }^{75}$ As such, the growth by CBD typically occurs under intermediate or oxygen-rich conditions, which are less favorable for the formation of a high density of $V_{\mathrm{O}}$ as reported by DFT calculations. ${ }^{16-17}$ To understand the present experimental data, the hydrogen-related defect luminescence positions were calculated within the Franck-Condon approximation in the framework of the effective one-dimensional configuration coordinate $Q$ as described in Refs. 21, 39. The zero phonon line energy $\left(E_{\mathrm{ZPL}}\right)$ and change in configuration coordinate $\Delta Q$ were computed using the DFT $+U$ method. The resulting emission energy ( $\left.E_{\text {emission }}\right)$ and absorption energy ( $\left.E_{\text {absorption }}\right)$ as reported in Table 1 were deduced from the following relations: $E_{\text {emission }}=E_{\mathrm{ZPL}}-\Delta E_{\mathrm{g}}$ and $E_{\text {absorption }}=$ $E_{\mathrm{ZPL}}+\Delta E_{\mathrm{e}}$ where $\Delta E_{\mathrm{g}}$ and $\Delta E_{\mathrm{e}}$ are the relaxation energies of the ground and excited states referred as Franck-Condon shifts. 


\begin{tabular}{|c|c|c|c|c|c|}
\hline \multirow{4}{*}{$V_{\mathrm{Zn}}$} & $\begin{array}{c}\text { Transition } \\
\text { level }\end{array}$ & $\begin{array}{c}E_{\text {transition }} \\
(\mathrm{eV})\end{array}$ & $\begin{array}{c}E_{\text {emission }} \\
(\mathrm{eV})\end{array}$ & $\begin{array}{c}E_{\text {ZPL }} \\
(\mathrm{eV})\end{array}$ & $\begin{array}{c}E_{\text {absorption }} \\
(\mathrm{eV})\end{array}$ \\
\cline { 2 - 6 } & $\varepsilon(+2 /+1)$ & 0.83 & 2.53 & 2.57 & 2.75 \\
\cline { 2 - 6 } & $\varepsilon(+1 / 0)$ & 0.85 & 2.48 & 2.55 & 2.65 \\
\cline { 2 - 6 } & $\varepsilon(0 /-1)$ & 0.96 & 2.19 & 2.44 & 2.71 \\
\hline \multirow{3}{*}{$V_{\mathrm{Zn}}-\mathrm{H}$} & $\varepsilon(-1 /-2)$ & 1.25 & 1.60 & 2.15 & 3.08 \\
\hline \multirow{3}{*}{$V_{\mathrm{Zn}}-2 \mathrm{H}$} & $\varepsilon(+2 /+1)$ & 0.87 & 2.49 & 2.53 & 2.74 \\
\cline { 2 - 6 } & $\varepsilon(+1 / 0)$ & 0.89 & 2.40 & 2.51 & 2.66 \\
\cline { 2 - 6 } & $\varepsilon(0 /-1)$ & 1.09 & 1.82 & 2.31 & 2.93 \\
\hline \multirow{2}{*}{$V_{\mathrm{Zn}}-3 \mathrm{H}$} & $\varepsilon(+2 /+1)$ & 0.89 & 2.46 & 2.51 & 2.96 \\
\hline \multirow{2}{*}{} & $\varepsilon(+1 / 0)$ & 0.92 & 2.29 & 2.48 & 2.86 \\
\hline
\end{tabular}

Table 1. Effective parameters for the calculated luminescence transitions, including $E_{\text {transition, }}$ $E_{\text {emission, }} E_{\text {ZPL }}$, and $E_{\text {absorption. }}$ The grey colored font enlightens the expected thermodynamic charge state of each defect when the Fermi level is close to the CBM.

The emission energy of $3.37 \mathrm{eV}$ corresponding to the $(+1 / 0)$ transition level of the $\left(V_{\mathrm{Zn}}-3 \mathrm{H}\right)$ defect complex lies in the NBE emission band. This statement supports the involvement of the $I_{5}$ line in that band and its assignment to the $(V \mathrm{Zn}-3 \mathrm{H})$ defect complex as suggested in Ref. 36 . Interestingly, the emission energy of $1.82 \mathrm{eV}$ corresponding to the $(0 /-1)$ transition level of the $\left(V_{\mathrm{Zn}}-\mathrm{H}\right)$ defect complex very well matches the energetic position of the red/orange emission band. This indicates the predominant involvement of that defect complex in the red/orange emission band. This assignment is in good agreement with a previous investigation suggesting the involvement of $V \mathrm{Zn}$-based defect complexes in the red emission band. ${ }^{85}$ The emission energy of $1.60 \mathrm{eV}$ corresponding to the (-1/-2) transition level of the $V \mathrm{Zn}$ may also be involved to some extent. The small shoulder in the red/orange emission band around $1.60 \mathrm{eV}$ is thus assigned to $V \mathrm{Zn}$. This assignment is in good agreement with a previous investigation suggesting that the red emission band in $\mathrm{ZnO}$ NWs grown by $\mathrm{CBD}$ is associated with the $V_{\mathrm{Zn} .}{ }^{45}$ Additionally, the emission energy of $2.29 \mathrm{eV}$ corresponding to the $(+1 / 0)$ transition level of the $\left(V_{\mathrm{Zn}}-2 \mathrm{H}\right)$ defect complex is also in very good agreement with the energetic position of the yellow/green emission 
band. This statement supports the involvement of the $\left(V_{\mathrm{Zn}}-2 \mathrm{H}\right)$ defect complex in that band. This assignment is in good agreement with previous investigations suggesting the involvement of $V \mathrm{Zn}$-based defect complexes in the green emission band of $\mathrm{ZnO} N W s .^{86-87}\left(V_{\mathrm{Zn}-\mathrm{H}}\right)$ and $\left(V_{\mathrm{Zn}-}\right.$ $2 \mathrm{H})$ defect complexes are thus formed in the bulk of $\mathrm{ZnO} \mathrm{NWs}$ and clearly assigned in the cathodoluminescence spectra. Other emission energies associated with different charge states of $V_{\mathrm{Zn}},\left(V_{\mathrm{Zn}}-\mathrm{H}\right)$ and $\left(V_{\mathrm{Zn}}-2 \mathrm{H}\right)$ may fit the energetic position of the yellow/green emission band, but i) the direct formation of these defects is unlikely when the Fermi level is close to the CBM and ii) their indirect formation through the capture of one or several holes from the corresponding stable defects with the expected charge state is unlikely as well in the bulk of $\mathrm{ZnO}$ NWs with a high electron density. The small discrepancies on the emission energy of these hydrogen-related defect complexes with previous DFT-based calculations ${ }^{21,39}$ are owing to i) the 192-atom supercells that were used in the present investigation in contrast to the previously used 96-atom supercells as well as to ii) the aforementioned DFT $+U$ approach that was used in the current study where in addition to the $U$ values for the $d$-states, $U$ values were also considered for the $s$ - or $p$-states. Moreover, one should notice that zinc dangling bonds with a presumable high density on the surfaces of $\mathrm{ZnO}$ NWs grown by CBD may also contribute significantly to the yellow/green emission band with an expected emission energy around 2.41 $\mathrm{eV}$.

The green/blue emission band centered at $2.65 \mathrm{eV}$ is expected to originate from surface defects in $\mathrm{ZnO}$ NWs. Following the electron-hole pair generation from the electron beam with an energy of $5 \mathrm{keV}$, holes migrate from the bulk of $\mathrm{ZnO} \mathrm{NWs}$ to their surfaces. The present phenomenon is due to the upward band bending related to a surface depletion region originating from the adsorbed oxygen ions. ${ }^{88}$ This creates a region close to the surface where holes are highly concentrated. They affect the charge states of the $V_{\mathrm{Zn}}$ and $\left(V_{\mathrm{Zn}}-n \mathrm{H}\right)$ defect complexes, which can deviate from the most stable configurations. Accordingly, we expect from Table 1 
that the green/blue emission band is mostly related to the $(+1 / 0)$ and $(+2 /+1)$ transition levels associated with the $V_{\mathrm{Zn}},\left(V_{\mathrm{Zn}}-\mathrm{H}\right)$, and $\left(V_{\mathrm{Zn}}-2 \mathrm{H}\right)$ defect complexes. In that sense, the green/blue emission band originates from the $V \mathrm{Zn}$ and hydrogen-related defects on the surfaces of $\mathrm{ZnO}$ NWs, which are probed under the typical conditions used with an electron beam or an UV radiation. This assignment is in good agreement with previous investigations attributing the green emission band to surface defects ${ }^{85,89}$ like $V_{\mathrm{Zn}},{ }^{90-91}$ which can exhibit a lower formation energy on the surfaces of $\mathrm{ZnO}$ NWs. ${ }^{92}$

In brief, the visible and ultra-violet emission bands are found to be mostly assigned to $V \mathrm{Zn}$ and $(V \mathrm{Zn}-n \mathrm{H})$ defect complexes located in the bulk and on the surfaces of unintentionally doped ZnO NWs grown by CBD.

\subsection{Raman scattering spectra and their assignment to crystal defects. To} complement the cathodoluminescence measurements, Raman spectroscopy collected on the ZnO NWs grown by CBD under standard conditions using the spontaneous growth approach was performed at room temperature. A typical Raman spectrum is presented in Figure 6a. The typical optical phonon modes that are characteristic of the wurtzite structure of $\mathrm{ZnO}$ occur in the wavenumber range of 50-900 $\mathrm{cm}^{-1} .{ }^{93}$ The Raman lines at 99, 378, 438, and $574 \mathrm{~cm}^{-1}$ are assigned to the $\mathrm{E}_{2}{ }^{\text {low }}, \mathrm{A}_{1}(\mathrm{TO}), \mathrm{E}_{2}^{\text {high }}$, and $\mathrm{A}_{1}(\mathrm{LO})$ modes, respectively. Second-order Raman lines at $203,483,666$, and $812 \mathrm{~cm}^{-1}$ correspond to $2 \mathrm{TA} / 2 \mathrm{E}_{2}{ }^{\text {low }}, 2 \mathrm{LA}, \mathrm{TA}+\mathrm{LO}$, and $\mathrm{LA}+\mathrm{TO}$ modes, respectively. The Raman line at $333 \mathrm{~cm}^{-1}$ is usually attributed to the $\mathrm{E}_{2}{ }^{\text {high }}-\mathrm{E}_{2}{ }^{\text {low }}$ mode, ${ }^{93}$ but it may also originate from the $1 \mathrm{~s} \rightarrow 2 \mathrm{p}$ donor state transition involving $\mathrm{H}_{\mathrm{BC}} .{ }^{34}$ Similarly, the shoulder around $273 \mathrm{~cm}^{-1}$ may also come from the $1 \mathrm{~s} \rightarrow 2 \mathrm{p}$ donor state transition involving Ho. ${ }^{34}$ No sign for the presence of additional modes occurs in that wavenumber range either, excluding again the possible incorporation of residual extrinsic impurities such as aluminium, gallium or indium. ${ }^{71-72,94}$ In the high wavenumber range of $2750-3000 \mathrm{~cm}^{-1}$, the sharp Raman lines correspond to antisymmetric and symmetric stretching bonds of $\mathrm{CH}_{\mathrm{x}}$ groups. ${ }^{95}$ The 
presence of carbon certainly originates from the adsorption of residual HMTA molecules on the surfaces of ZnO NWs. It is well-known that HMTA as one of the two chemical precursors during the CBD process adsorbs on the $m$-plane sidewalls of $\mathrm{ZnO} \mathrm{NWs.}{ }^{62,}{ }^{96-97}$ Its use is achieved to inhibit the radial growth of $\mathrm{ZnO}$ NWs and increase their aspect ratio. No sign for the incorporation of carbon in the bulk of $\mathrm{ZnO}$ NWs occurs. In particular, the typical Z-lines attributed to carbon-related defects in photoluminescence spectra have been shown in $\mathrm{ZnO}$ NWs grown by metal-organic vapor phase epitaxy, ${ }^{98}$ but their presence has not been revealed in $\mathrm{ZnO}$ NWs grown by CBD. ${ }^{14}$ This supports the presence of carbon mostly on the surfaces of ZnO NWs. Correlatively, the intense Raman line at $3078 \mathrm{~cm}^{-1}$ can be assigned to nitrogenrelated bonds. ${ }^{95}$ Again, the presence of nitrogen through the formation of N-H groups likely comes, to a large extent, from the adsorption of residual HMTA molecules on the surfaces of ZnO NWs. ${ }^{62,96-97}$ No sign for the presence of additional modes related to substitutional nitrogen on the oxygen lattice site occurs. ${ }^{99}$ The formation of highly stable N-H like defects in the bulk of ZnO NWs cannot be excluded, but they typically act as neutral defect complexes. ${ }^{100-102}$ As a result, they cannot account for the high electron density of these $\mathrm{ZnO}$ NWs despite their possible involvement. More importantly, the signature of hydrogen on the surface and in the bulk of $\mathrm{ZnO}$ NWs largely occurs in the wavenumber range of $3200-3750 \mathrm{~cm}^{-1}$ in the Raman spectrum. The dominant Raman line centered at $3575 \mathrm{~cm}^{-1}$ and with a FWHM of $70.5 \mathrm{~cm}^{-1}$ is assigned to $\mathrm{HBC}_{\mathrm{BC}}$ as previously reported in Refs. 33,103 . The shoulder around $3500 \mathrm{~cm}^{-1}$ is due to the $\mathrm{O}-\mathrm{H}$ bonds on the surface of $\mathrm{ZnO} \mathrm{NWs}$, as typically assigned in Refs. 33, 104-105. More interestingly, the other intense Raman band centered at lower wavenumbers is basically composed of three distinct components as shown in Figure $\mathbf{6 b}$. They are generally assigned to the $\left(V_{\mathrm{Zn}}-n \mathrm{H}\right)$ defect complexes. The $\left(V_{\mathrm{Zn}}-\mathrm{H}\right)$ defect complex results in Raman and infrared absorption lines lying in the range of $3306-3418 \mathrm{~cm}^{-1} \cdot{ }^{21,33}$ In contrast, the $\left(V_{\mathrm{Zn}}-2 \mathrm{H}\right)$ defect complex leads to infrared absorption lines pointing at 3312 and $3349 \mathrm{~cm}^{-1},{ }^{33}$ whereas the $\left(V \mathrm{Zn}^{-}\right.$ 
$3 \mathrm{H})$ defect complex gives rise to infrared absorption lines pointing at 3303 and $3321 \mathrm{~cm}^{-1}, 38$ respectively. The presence of these hydrogen-related defects in the Raman spectrum is in very good agreement with the cathodoluminescence spectrum in Figure 5. This confirms their formation with a significant amount in ZnO NWs grown by CBD under standard conditions using the spontaneous growth approach.
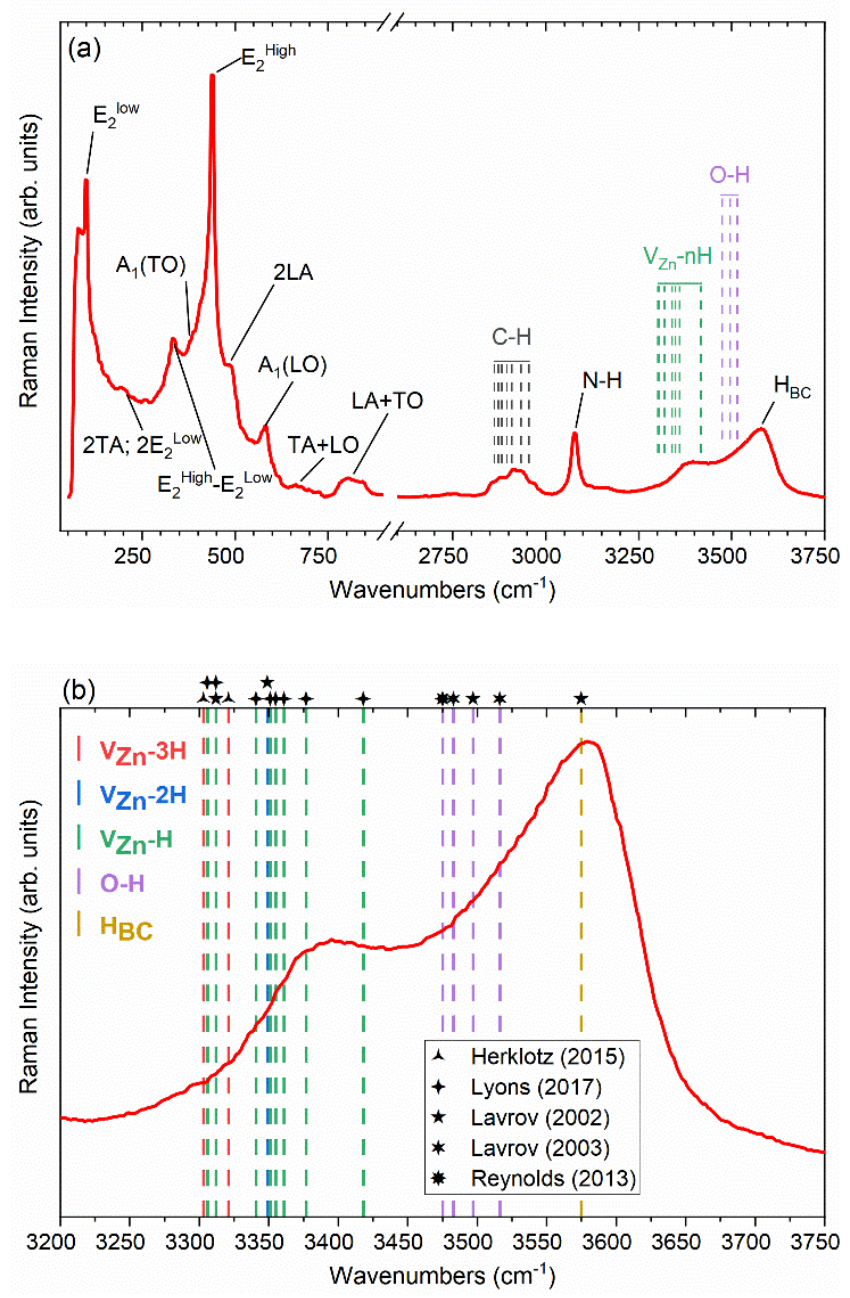

Figure 6. (a) Typical Raman spectrum of unintentionally doped ZnO NWs grown by CBD under standard conditions using the spontaneous growth approach. (b) Corresponding high wavenumber region. The insets represent the calculated and experimental vibrational frequencies from Raman and infrared absorption spectroscopy as inferred from Refs. 21, 33, $38,104-105$.

\section{DISCUSSION}


$\mathrm{ZnO}$ NWs can be formed by a large number of physical and chemical deposition techniques in vapor phase or in solution by using the spontaneous growth approach (i.e. without any catalyst) owing to the highly anisotropic degree of the wurtzite structure. Their high electrical conductivity corresponding to a high electron density has been revealed regardless of the deposition techniques used ${ }^{12,65}$ and in the present investigation as well. However, the origin of that high electron density should be distinguished and strongly depends on the deposition techniques used. While the high electron density in $\mathrm{ZnO}$ NWs grown by vapor phase deposition techniques has commonly been attributed to the significant incorporation of residual extrinsic impurities that inherently occur in the dedicated chamber, ${ }^{65}$ it has been revealed here that the situation of $\mathrm{ZnO} \mathrm{NWs}$ grown by CBD strongly differs. The metallic electrical conduction of unintentionally doped $\mathrm{ZnO}$ NWs and the correlated high electron density above $2.7 \times 10^{18} \mathrm{~cm}^{-}$ ${ }^{3}$ is instead due to the large incorporation of hydrogen in their center. Both cathodoluminescence and Raman spectroscopy measurements have clearly revealed the presence of $\mathrm{HBC}_{\mathrm{BC}}$ and $\left(V_{\mathrm{Zn}}-\right.$ $n \mathrm{H})$ defect complexes with $n=1-3$ in the center of $\mathrm{ZnO}$ NWs, which is in excellent agreement with DFT calculations showing their low formation energy when the Fermi level is close to the CBM. While $\mathrm{H}_{\mathrm{BC}}$ is a shallow donor that accounts, to a significant extent, for the source of $\mathrm{n}$ type conductivity of $\mathrm{ZnO} \mathrm{NWs}$ grown by $\mathrm{CBD}$, the situation of the $\left(V_{\mathrm{Zn}}-n \mathrm{H}\right)$ defect complexes strongly depends on the number $n$ of involved $\mathrm{H}_{\mathrm{i}}$ atoms. The formation of all the $\left(V_{\mathrm{Zn}}-\mathrm{H}\right),\left(V_{\mathrm{Zn}-}\right.$ $2 \mathrm{H})$, and $(\mathrm{Vn}-3 \mathrm{H})$ defect complexes has been shown in the cathodoluminescence and Raman spectra. However, their electrical activity is highly distinct. The $\left(V_{\mathrm{Zn}}-\mathrm{H}\right)$ and $\left(V_{\mathrm{Zn}}-2 \mathrm{H}\right)$ defect complexes acting as a deep acceptor and a neutral complex, respectively, have a limited impact on the electrical properties of $\mathrm{ZnO} \mathrm{NWs}$ grown by $\mathrm{CBD}$. Nevertheless, they are largely formed in the center of $\mathrm{ZnO}$ NWs owing to their low formation energy. Also they have a high impact on the optical properties of $\mathrm{ZnO} \mathrm{NWs}$, specifically through the respective i) red-orange and yellow/green emission bands when located in the bulk and ii) green/blue emission band when 
located on the surfaces. In contrast, the $\left(\mathrm{V}_{\mathrm{Zn}}-3 \mathrm{H}\right)$ defect complex acting as a shallow donor with a very low formation energy regardless of the Fermi level in the bandgap should be considered as one of the major sources of n-type conductivity in ZnO NWs grown by CBD. Additionally, the role of Ho as a further shallow donor is also expected to play a significant role here. By considering that the hydrogen-related shallow donors are partially ionized, we further expect that the hydrogen concentration in $\mathrm{ZnO}$ NWs is huge and above $1-5 \times 10^{19} \mathrm{~cm}^{-3}$. The present findings promote hydrogen engineering as a capital issue in the field. They reveal that the hydrogen engineering in $\mathrm{ZnO} \mathrm{NWs}$ grown by $\mathrm{CBD}$ is crucial for tuning their optical and electrical properties as an important issue for improving the performance of nanoscale devices integrating this type of objects. They further open the way for innovative strategies aiming at increasing or decreasing the density of hydrogen-related defects in $\mathrm{ZnO}$ NWs depending on the devices targeted, including post-deposition thermal heat treatments under different atmospheres and plasma for instance.

\section{CONCLUSION}

In summary, we have shown by four-point probe resistivity measurements that unintentionally doped $\mathrm{ZnO}$ NWs spontaneously grown by CBD under standard conditions exhibit a high electrical conductivity with electron densities lying in the range of $2.7 \times 10^{18}$ to $3.1 \times 10^{19} \mathrm{~cm}^{-3}$. Most of them have a metallic electrical conduction. This has been attributed from cathodoluminescence and Raman spectroscopy supported by DFT calculations to the formation of $\mathrm{HBC}_{\mathrm{BC}}$ and $\left(V_{Z n}-3 \mathrm{H}\right)$ defect complexes acting as two shallow donors with a very low formation energy. Additionally, the assignment of the visible and ultra-violet emission bands in the cathodoluminescence spectra has been revisited with the help of DFT calculations, revealing the significant roles of $V_{\mathrm{Zn}}$ and $\left(V_{Z n}-n \mathrm{H}\right)$ defect complexes located in the bulk and on the surfaces of $\mathrm{ZnO}$ NWs. The NBE emission band has been assigned to the $\left(V_{\mathrm{Zn}}-3 \mathrm{H}\right)$ defect complex. In contrast, the red/orange and yellow/green emission bands lying at 1.86 and 2.25 
$\mathrm{eV}$ have been attributed to the $V_{\mathrm{Zn}}$ and $\left(V_{\mathrm{Zn}}-\mathrm{H}\right)$ defect complex as well as to the $\left(V_{\mathrm{Zn}}-2 \mathrm{H}\right)$ defect complex in the bulk of $\mathrm{ZnO} \mathrm{NWs}$, respectively. Importantly, the green/blue emission band at $2.65 \mathrm{eV}$ has been assigned to the $V \mathrm{Zn},\left(V_{\mathrm{Zn}-\mathrm{H}}\right)$, and $\left(V_{\mathrm{Zn}}-2 \mathrm{H}\right)$ defects located on the surfaces of ZnO NWs. These findings unambiguously identify the predominant native and extrinsic defects in unintentionally doped $\mathrm{ZnO}$ NWs grown by CBD to hydrogen-related defects, governing in turn their electronic structure properties. They further open many perspectives for optimizing the related optical and electrical properties of $\mathrm{ZnO}$ NWs as a critical requirement for a large number of nanoscale engineering devices.

\section{ASSOCIATED CONTENT}

Typical evolution of $R / l$ as a function of the electron beam dose (Figure S1). Electronic band structures of the pristine $\mathrm{ZnO}$ and defected supercells (Figure S2).

\section{ACKNOWLEDGEMENTS}

The authors acknowledge the financial support from the French Research National Agency through the project ROLLER (ANR-17-CE09-0033). J.V. held a doctoral fellowship from the ROLLER project. This research has further benefited from some of the characterization equipment of the Grenoble INP-CMTC platform. This work was supported by computational time granted from the Greek Research \& Technology Network (GRNET) in the 'ARIS' National HPC infrastructure under the project AIMONACA (pr008002).

\section{References}

1. Wang, Z. L. Towards Self-Powered Nanosystems: From Nanogenerators to Nanopiezotronics. Adv. Funct. Mater. 2008, 18, 3553-3567.

2. Tian, W.; Lu, H.; Li, L. Nanoscale Ultraviolet Photodetectors Based on One-Dimensional Metal Oxide Nanostructures. Nano Res. 2015, 8, 382-405.

3. Willander, M.; Nur, O.; Zhao, Q. X.; Yang, L. L.; Lorenz, M.; Cao, B. Q.; Zuniga-Perez, J.; Czekalla, C.; Zimmermann, G.; Grundmann, M.; et al. Zinc Oxide Nanorod Based Photonic Devices: Recent Progress in Growth, Light Emitting Diodes and Lasers. Nanotechnology 2009, 20, 332001.

4. Consonni, V.; Briscoe, J.; Karber, E.; Li, X.; Cossuet, T. ZnO Nanowires for Solar Cells: A Comprehensive Review. Nanotechnology 2019, 30, 362001.

5. Zhu, L.; Zeng, W. Room-Temperature Gas Sensing of ZnO-Based Gas Sensor: A Review. Sens. Actuator A-Phys. 2017, 267, 242-261. 
6. Vayssieres, L. Growth of Arrayed Nanorods and Nanowires of $\mathrm{ZnO}$ from Aqueous Solutions. Adv. Mater. 2003, 15, 464-466.

7. Xu, S.; Wang, Z. L. One-Dimensional ZnO Nanostructures: Solution Growth and Functional Properties. Nano Res. 2011, 4, 1013-1098.

8. Wei, Y. G.; Wu, W. Z.; Guo, R.; Yuan, D. J.; Das, S. M.; Wang, Z. L. Wafer-Scale High-Throughput Ordered Growth of Vertically Aligned ZnO Nanowire Arrays. Nano Lett. 2010, 10, 3414-3419.

9. Erdelyi, R.; Nagata, T.; Rogers, D. J.; Teherani, F. H.; Horvath, Z. E.; Labadi, Z.; Baji, Z.; Wakayama, Y.; Volk, J. Investigations into the Impact of the Template Layer on ZnO Nanowire Arrays Made Using Low Temperature Wet Chemical Growth. Cryst. Growth Des. 2011, 11, 2515-2519.

10. Consonni, V.; Sarigiannidou, E.; Appert, E.; Bocheux, A.; Guillemin, S.; Donatini, F.; Robin, I. C.; Kioseoglou, J.; Robaut, F. Selective Area Growth of Well-Ordered ZnO Nanowire Arrays with Controllable Polarity. ACS Nano 2014, 8, 4761-4770.

11. Baxter, J. B.; Schmuttenmaer, C. A. Conductivity of ZnO Nanowires, Nanoparticles, and Thin Films Using Time-Resolved Terahertz Spectroscopy. J. Phys. Chem. B 2006, 110, 25229-25239.

12. Lord, A. M.; Maffeis, T. G.; Walton, A. S.; Kepaptsoglou, D. M.; Ramasse, Q. M.; Ward, M. B.; Koble, J.; Wilks, S. P. Factors That Determine and Limit the Resistivity of High-Quality Individual ZnO Nanowires. Nanotechnology 2013, 24, 435706.

13. Opoku, C.; Dahiya, A. S.; Cayrel, F.; Poulin-Vittrant, G.; Alquier, D.; Camara, N. Fabrication of Field-Effect Transistors and Functional Nanogenerators Using Hydrothermally Grown ZnO Nanowires. RSC Adv. 2015, 5, 69925-69931.

14. Cossuet, T.; Donatini, F.; Lord, A. M.; Appert, E.; Pernot, J.; Consonni, V. Polarity-Dependent High Electrical Conductivity of ZnO Nanorods and Its Relation to Hydrogen. J. Phys. Chem. C 2018, 122, 22767-22775.

15. Wang, L.; Guillemin, S.; Chauveau, J. M.; Sallet, V.; Jomard, F.; Brenier, R.; Consonni, V.; Bremond, G. Characterization of Carrier Concentration in Zno Nanowires by Scanning Capacitance Microscopy. Phys. Status Solidi C 2016, 13, 576-580.

16. Janotti, A.; Van de Walle, C. G. Fundamentals of Zinc Oxide as a Semiconductor. Rep. Prog. Phys. 2009, 72, 126501.

17. McCluskey, M. D.; Jokela, S. J. Defects in ZnO. J. Appl. Phys. 2009, 106, 071101.

18. Janotti, A.; Van de Walle, C. G. Oxygen Vacancies in ZnO. Appl. Phys. Lett. 2005, 87, 122102.

19. Paudel, T. R.; Lambrecht, W. R. L. First-Principles Calculation of the O Vacancy in ZnO: A SelfConsistent Gap-Corrected Approach. Phys. Rev. B 2008, 77, 205202.

20. Janotti, A.; Van de Walle, C. G. Native Point Defects in ZnO. Phys. Rev. B 2007, 76, 165202.

21. Lyons, J. L.; Varley, J. B.; Steiauf, D.; Janotti, A.; Van de Walle, C. G. First-Principles Characterization of Native-Defect-Related Optical Transitions in ZnO. J. Appl. Phys. 2017, 122, 035704.

22. Selim, F. A.; Weber, M. H.; Solodovnikov, D.; Lynn, K. G. Nature of Native Defects in ZnO. Phys. Rev. Lett. 2007, 99, 085502.

23. Oba, F.; Togo, A.; Tanaka, I.; Paier, J.; Kresse, G. Defect Energetics in ZnO: A Hybrid HartreeFock Density Functional Study. Phys. Rev. B 2008, 77, 245202.

24. Clark, S. J.; Robertson, J.; Lany, S.; Zunger, A. Intrinsic Defects in ZnO Calculated by Screened Exchange and Hybrid Density Functionals. Phys. Rev. B 2010, 81, 115311.

25. Alkauskas, A.; Pasquarello, A. Band-Edge Problem in the Theoretical Determination of Defect Energy Levels: The O Vacancy in ZnO as a Benchmark Case. Phys. Rev. B 2011, 84, 125206.

26. Buckeridge, J.; Catlow, C. R. A.; Farrow, M. R.; Logsdail, A. J.; Scanlon, D. O.; Keal, T. W.; Sherwood, P.; Woodley, S. M.; Sokol, A. A.; Walsh, A. Deep Vs Shallow Nature of Oxygen Vacancies and Consequent N-Type Carrier Concentrations in Transparent Conducting Oxides. Phys. Rev. Mater. 2018, $2,054604$.

27. Van de Walle, C. G. Hydrogen as a Cause of Doping in Zinc Oxide. Phys. Rev. Lett. 2000, 85, 1012-1015.

28. Janotti, A.; Van de Walle, C. G. Hydrogen Multicentre Bonds. Nat. Mater. 2007, 6, 44-47.

29. Wardle, M. G.; Goss, J. P.; Briddon, P. R. Theory of Fe, Co, Ni, Cu, and Their Complexes with Hydrogen in ZnO. Phys. Rev. B 2005, 72, 155108. 
30. Karazhanov, S. Z.; Marstein, E. S.; Holt, A. Hydrogen Complexes in Zn Deficient ZnO. J. Appl. Phys. 2009, 105, 033712.

31. Hofmann, D. M.; Hofstaetter, A.; Leiter, F.; Zhou, H. J.; Henecker, F.; Meyer, B. K.; Orlinskii, S. B.; Schmidt, J.; Baranov, P. G. Hydrogen: A Relevant Shallow Donor in Zinc Oxide. Phys. Rev. Lett. 2002, $88,045504$.

32. Repp, S.; Weber, S.; Erdem, E. Defect Evolution of Nonstoichiometric ZnO Quantum Dots. J. Phys. Chem. C 2016, 120, 25124-25130.

33. Lavrov, E. V.; Weber, J.; Borrnert, F.; Van de Walle, C. G.; Helbig, R. Hydrogen-Related Defects in ZnO Studied by Infrared Absorption Spectroscopy. Phys. Rev. B 2002, 66, 165205.

34. Lavrov, E. V.; Herklotz, F.; Weber, J. Identification of Two Hydrogen Donors in ZnO. Phys. Rev. B 2009, 79, 165210.

35. Meyer, B. K.; Alves, H.; Hofmann, D. M.; Kriegseis, W.; Forster D.; Bertram, F.; Christen, J.; Hoffmann, A.; Strassburg, M.; Dworzak, M.; et al. Bound Exciton and Donor-Acceptor Pair Recombinations in ZnO. Phys. Status Solidi B 2004, 241, 231-260.

36. Heinhold, R.; Neiman, A.; Kennedy, J. V.; Markwitz, A.; Reeves, R. J.; Allen, M. W. HydrogenRelated Excitons and Their Excited-State Transitions in ZnO. Phys. Rev. B 2017, 95, 054120.

37. Kossmann, J.; Hattig, C. Investigation of Interstitial Hydrogen and Related Defects in ZnO. Phys. Chem. Chem. Phys. 2012, 14, 16392-16399.

38. Herklotz, F.; Hupfer, A.; Johansen, K. M.; Svensson, B. G.; Koch, S. G.; Lavrov, E. V. Infrared Absorption on a Complex Comprising Three Equivalent Hydrogen Atoms in ZnO. Phys. Rev. B 2015, 92, 055203.

39. Frodason, Y. K.; Johansen, K. M.; Bjorheim, T. S.; Svensson, B. G.; Alkauskas, A. Zn VacancyDonor Impurity Complexes in ZnO. Phys. Rev. B 2018, 97, 104109.

40. Djurisic, A. B.; Leung, Y. H. Optical Properties of ZnO Nanostructures. Small 2006, 2, 944-961.

41. Willander, M.; Nur, O.; Sadaf, J. R.; Qadir, M. I.; Zaman, S.; Zainelabdin, A.; Bano, N.; Hussain, I. Luminescence from Zinc Oxide Nanostructures and Polymers and Their Hybrid Devices. Materials 2010, 3, 2643-2667.

42. Lin, C. C.; Chen, H. P.; Liao, H. C.; Chen, S. Y. Enhanced Luminescent and Electrical Properties of Hydrogen-Plasma ZnO Nanorods Grown on Wafer-Scale Flexible Substrates. Appl. Phys. Lett. 2005, 86, 183103.

43. Huang, X. H.; Tay, C. B.; Zhan, Z. Y.; Zhang, C.; Zheng, L. X.; Venkatesan, T.; Chua, S. J. Universal Photoluminescence Evolution of Solution-Grown ZnO Nanorods with Annealing: Important Role of Hydrogen Donor. Crystengcomm 2011, 13, 7032-7036.

44. Kushwaha, A.; Aslam, M. Hydrogen-Incorporated ZnO Nanowire Films: Stable and High Electrical Conductivity. J. Phys. D-Appl. Phys. 2013, 46, 485104.

45. Anantachaisilp, S.; Smith, S. M.; Ton-That, C.; Osotchan, T.; Moon, A. R.; Phillips, M. R. Tailoring Deep Level Surface Defects in ZnO Nanorods for High Sensitivity Ammonia Gas Sensing. J. Phys. Chem. C 2014, 118, 27150-27156.

46. Zhu, Q.; Xie, C. S.; Li, H. Y.; Yang, C. Q.; Zhang, S. P.; Zeng, D. W. Selectively Enhanced Uv and Nir Photoluminescence from a Degenerate ZnO Nanorod Array Film. J. Mater. Chem. C 2014, 2, 45664580.

47. Gurylev, V.; Su, C. Y.; Perng, T. P. Hydrogenated ZnO Nanorods with Defect-Induced Visible Light-Responsive Photoelectrochemical Performance. Appl. Surf. Sci. 2017, 411, 279-284.

48. Huang, X. H.; Zhan, Z. Y.; Pramoda, K. P.; Zhang, C.; Zheng, L. X.; Chua, S. J. Correlating the Enhancement of UV Luminescence from Solution-Grown ZnO Nanorods with Hydrogen Doping. Crystengcomm 2012, 14, 5163-5165.

49. Urgessa, Z. N.; Botha, J. R.; Eriksson, M. O.; Mbulanga, C. M.; Dobson, S. R.; Djiokap, S. R. T.; Karlsson, K. F.; Khranovskyy, V.; Yakimova, R.; Holtz, P. O. Low Temperature near Band Edge Recombination Dynamics in ZnO Nanorods. J. Appl. Phys. 2014, 116, 123506.

50. Barbagiovanni, E. G.; Reitano, R.; Franzo, G.; Strano, V.; Terrasi, A.; Mirabella, S. Radiative Mechanism and Surface Modification of Four Visible Deep Level Defect States in ZnO Nanorods. Nanoscale 2016, 8, 995-1006. 
51. Blochl, P. E. Projector Augmented-Wave Method. Phys. Rev. B 1994, 50, 17953-17979.

52. Kresse, G.; Joubert, D. From Ultrasoft Pseudopotentials to the Projector Augmented-Wave Method. Phys. Rev. B 1999, 59, 1758-1775.

53. Perdew, J. P.; Burke, K.; Ernzerhof, M. Generalized Gradient Approximation Made Simple. Phys. Rev. Lett. 1996, 77, 3865-3868.

54. Perdew, J. P.; Burke, K.; Ernzerhof, M. Generalized Gradient Approximation Made Simple (Vol 77, Pg 3865, 1996). Phys. Rev. Lett. 1997, 78, 1396-1396.

55. Erhart, P.; Albe, K.; Klein, A. First-Principles Study of Intrinsic Point Defects in ZnO: Role of Band Structure, Volume Relaxation, and Finite-Size Effects. Phys. Rev. B 2006, 73, 205203.

56. Lathiotakis, N. N.; Andriotis, A. N.; Menon, M. Codoping: A Possible Pathway for Inducing Ferromagnetism in ZnO. Phys. Rev. B 2008, 78, 193311.

57. Sheetz, R. M.; Ponomareva, I.; Richter, E.; Andriotis, A. N.; Menon, M. Defect-Induced Optical Absorption in the Visible Range in ZnO Nanowires. Phys. Rev. B 2009, 80, 195314.

58. Freysoldt, C.; Neugebauer, J.; Van de Walle, C. G. Fully Ab Initio Finite-Size Corrections for Charged-Defect Supercell Calculations. Phys. Rev. Lett. 2009, 102, 016402.

59. Freysoldt, C.; Neugebauer, J.; Van de Walle, C. G. Electrostatic Interactions between Charged Defects in Supercells. Phys. Status Solidi B 2011, 248, 1067-1076.

60. Freysoldt, C.; Grabowski, B.; Hickel, T.; Neugebauer, J.; Kresse, G.; Janotti, A.; Van de Walle, C. G. First-Principles Calculations for Point Defects in Solids. Rev. Mod. Phys. 2014, 86, 253.

61. Guillemin, S.; Appert, E.; Roussel, H.; Doisneau, B.; Parize, R.; Boudou, T.; Bremond, G.; Consonni, V. Controlling the Structural Properties of Single Step, Dip Coated ZnO Seed Layers for Growing Perfectly Aligned Nanowire Arrays. J. Phys. Chem. C 2015, 119, 21694-21703.

62. Parize, R.; Garnier, J.; Chaix-Pluchery, O.; Verrier, C.; Appert, E.; Consonni, V. Effects of Hexamethylenetetramine on the Nucleation and Radial Growth of $\mathrm{ZnO}$ Nanowires by Chemical Bath Deposition. J. Phys. Chem. C 2016, 120, 5242-5250.

63. Cossuet, T.; Roussel, H.; Chauveau, J. M.; Chaix-Pluchery, O.; Thomassin, J. L.; Appert, E.; Consonni, V. Well-Ordered ZnO Nanowires with Controllable Inclination on Semipolar Zno Surfaces by Chemical Bath Deposition. Nanotechnology 2018, 29, 475601.

64. Donatini, F.; Sartel, C.; Sallet, V.; Pernot, J. Electron Beam Dose Dependence of Surface Recombination Velocity and Surface Space Charge in Semiconductor Nanowires. Nanotechnology 2017, 28, 235701.

65. Bugallo, A. D.; Donatini, F.; Sartel, C.; Sallet, V.; Pernot, J. Metallic Core Conduction in Unintentionally Doped ZnO Nanowire. Appl. Phys. Express 2015, 8, 025001.

66. Johannes, A.; Niepelt, R.; Gnauck, M.; Ronning, C. Persistent Ion Beam Induced Conductivity in Zinc Oxide Nanowires. Appl. Phys. Lett. 2011, 99, 252105.

67. Park, W. I.; Kim, J. S.; Yi, G. C.; Bae, M. H.; Lee, H. J. Fabrication and Electrical Characteristics of High-Performance ZnO Nanorod Field-Effect Transistors. Appl. Phys. Lett. 2004, 85, 5052-5054.

68. Kalblein, D.; Weitz, R. T.; Bottcher, H. J.; Ante, F.; Zschieschang, U.; Kern, K.; Klauk, H. Top-Gate ZnO Nanowire Transistors and Integrated Circuits with Ultrathin Self-Assembled Monolayer Gate Dielectric. Nano Lett. 2011, 11, 5309-5315.

69. Fang, Z. H.; Robin, E.; Rozas-Jimenez, E.; Cros, A.; Donatini, F.; Mollard, N.; Pernot, J.; Daudin, B. Si Donor Incorporation in GaN Nanowires. Nano Lett. 2015, 15, 6794-6801.

70. Brochen, S.; Feuillet, G.; Santailler, J. L.; Obrecht, R.; Lafossas, M.; Ferret, P.; Chauveau, J. M.; Pernot, J. Non-Metal to Metal Transition in N-Type ZnO Single Crystal Materials. J. Appl. Phys. 2017, $121,095704$.

71. Verrier, C.; Appert, E.; Chaix-Pluchery, O.; Rapenne, L.; Rafhay, Q.; Kaminski-Cachopo, A.; Consonni, V. Effects of the $\mathrm{pH}$ on the Formation and Doping Mechanisms of $\mathrm{ZnO}$ Nanowires Using Aluminum Nitrate and Ammonia. Inorg. Chem. 2017, 56, 13111-13122.

72. Gaffuri, P.; Appert, E.; Chaix-Pluchery, O.; Rapenne, L.; Salaun, M.; Consonni, V. The Path of Gallium from Chemical Bath into ZnO Nanowires: Mechanisms of Formation and Incorporation. Inorg. Chem. 2019, 58, 10269-10279. 
73. McPeak, K. M.; Becker, M. A.; Britton, N. G.; Majidi, H.; Bunker, B. A.; Baxter, J. B. In Situ X-Ray Absorption near-Edge Structure Spectroscopy of ZnO Nanowire Growth During Chemical Bath Deposition. Chem. Mater. 2010, 22, 6162-6170.

74. Cheng, J. J.; Nicaise, S. M.; Berggren, K. K.; Gradecak, S. Dimensional Tailoring of Hydrothermally Grown Zinc Oxide Nanowire Arrays. Nano Lett. 2016, 16, 753-759.

75. Lausecker, C.; Salem, B.; Baillin, X.; Consonni, V. Modeling the Elongation of Nanowires Grown by Chemical Bath Deposition Using a Predictive Approach. J. Phys. Chem. C 2019, 123, 29476-29483.

6. Herklotz, F.; Lavrov, E. V.; Weber, J. Charge States of a Hydrogen Defect ( $3326 \mathrm{~cm}^{-1}$ Line) in ZnO. Physica B 2012, 407, 2883-2885.

77. Bastin, D.; Lavrov, E. V.; Weber, J. Identification of a Metastable State of the $\mathrm{V}_{\mathrm{zn}} \mathrm{H}_{2}$ Defect in ZnO. Physica B 2012, 407, 2919-2922.

78. Vlasenko, L. S.; Watkins, G. D. Optical Detection of Electron Paramagnetic Resonance in RoomTemperature Electron-Irradiated ZnO. Phys. Rev. B 2005, 71, 125210.

79. Panigrahy, B.; Aslam, M.; Misra, D. S.; Ghosh, M.; Bahadur, D. Defect-Related Emissions and Magnetization Properties of ZnO Nanorods. Adv. Funct. Mater. 2010, 20, 1161-1165.

80. Kushwaha, A.; Aslam, M. Defect Induced High Photocurrent in Solution Grown Vertically Aligned ZnO Nanowire Array Films. J. Appl. Phys. 2012, 112, 054316.

81. Wong, K. M.; Fang, Y. G.; Devaux, A.; Wen, L. Y.; Huang, J.; De Cola, L.; Lei, Y. Assorted Analytical and Spectroscopic Techniques for the Optimization of the Defect-Related Properties in Size-Controlled ZnO Nanowires. Nanoscale 2011, 3, 4830-4839.

82. Barbagiovanni, E. G.; Strano, V.; Franzo, G.; Crupi, I.; Mirabella, S. Photoluminescence Transient Study of Surface Defects in ZnO Nanorods Grown by Chemical Bath Deposition. Appl. Phys. Lett. 2015, $106,093108$.

83. Kaftelen, H.; Ocakoglu, K.; Thomann, R.; Tu, S.; Weber, S.; Erdem, E. EPR and Photoluminescence Spectroscopy Studies on the Defect Structure of ZnO Nanocrystals. Phys. Rev. B 2012, 86, 014113.

84. Parashar, S. K. S.; Murty, B. S.; Repp, S.; Weber, S.; Erdem, E. Investigation of Intrinsic Defects in Core-Shell Structured ZnO Nanocrystals. J. Appl. Phys. 2012, 111, 113712.

85. Djurisic, A. B.; Leung, Y. H.; Tam, K. H.; Hsu, Y. F.; Ding, L.; Ge, W. K.; Zhong, Y. C.; Wong, K. S.; Chan, W. K.; Tam, H. L.; et al. Defect Emissions in ZnO Nanostructures. Nanotechnology 2007, 18, 095702.

86. Leung, Y. H.; Chen, X. Y.; Ng, A. M. C.; Guo, M. Y.; Liu, F. Z.; Djurisic, A. B.; Chan, W. K.; Shi, X. Q.; Van Hove, M. A. Green Emission in ZnO Nanostructures-Examination of the Roles of Oxygen and Zinc Vacancies. Appl. Surf. Sci. 2013, 271, 202-209.

87. Tam, K. H.; Cheung, C. K.; Leung, Y. H.; Djurisic, A. B.; Ling, C. C.; Beling, C. D.; Fung, S.; Kwok, W. M.; Chan, W. K.; Philipps, D. L.; et al. Defects in ZnO Nanorods Prepared by a Hydrothermal Method. J. Phys. Chem. B 2006, 110, 20865-20871.

88. Soci, C.; Zhang, A.; Xiang, B.; Dayeh, S. A.; Aplin, D. P. R.; Park, J.; Bao, X. Y.; Lo, Y. H.; Wang, D. ZnO Nanowire UV Photodetectors with High Internal Gain. Nano Lett. 2007, 7, 1003-1009.

89. Kennedy, O. W.; White, E. R.; Howkins, A.; Williams, C. K.; Boyd, I. W.; Warburton, P. A.; Shaffer, M. S. P. Mapping the Origins of Luminescence in ZnO Nanowires by STEM-CL. J. Phys. Chem. Lett. 2019, 10, 386-392.

90. Fabbri, F.; Villani, M.; Catellani, A.; Calzolari, A.; Cicero, G.; Calestani, D.; Calestani, G.; Zappettini, A.; Dierre, B.; Sekiguchi, T.; et al. Zn Vacancy Induced Green Luminescence on Non-Polar Surfaces in ZnO Nanostructures. Sci. Rep. 2014, 4, 5158.

91. Barbagiovanni, E. G.; Strano, V.; Franzo, G.; Mirabella, S. The Role of Zn Vacancies in UV Sensing with ZnO Nanorods. Appl. Phys. Lett. 2016, 109, 143104.

92. Fang, D. Q.; Zhang, R. Q. Size Effects on Formation Energies and Electronic Structures of Oxygen and Zinc Vacancies in ZnO Nanowires: A First-Principles Study. J. Appl. Phys. 2011, 109, 044306.

93. Cusco, R.; Alarcon-Llado, E.; Ibanez, J.; Artus, L.; Jimenez, J.; Wang, B. G.; Callahan, M. J. Temperature Dependence of Raman Scattering in ZnO. Phys. Rev. B 2007, 75, 165202. 
94. Bundesmann, C.; Ashkenov, N.; Schubert, M.; Spemann, D.; Butz, T.; Kaidashev, E. M.; Lorenz, M.; Grundmann, M. Raman Scattering in ZnO Thin Films Doped with Fe, Sb, Al, Ga, and Li. Appl. Phys. Lett. 2003, 83, 1974-1976.

95. Nickel, N. H.; Fleischer, K. Hydrogen Local Vibrational Modes in Zinc Oxide. Phys. Rev. Lett. 2003, 90, 197402.

96. Sugunan, A.; Warad, H. C.; Boman, M.; Dutta, J. Zinc Oxide Nanowires in Chemical Bath on Seeded Substrates: Role of Hexamine. J. Sol-Gel Sci. Technol. 2006, 39, 49-56.

97. Strano, V.; Urso, R. G.; Scuderi, M.; Iwu, K. O.; Simone, F.; Ciliberto, E.; Spinella, C.; Mirabella, S. Double Role of HMTA in ZnO Nanorods Grown by Chemical Bath Deposition. J. Phys. Chem. C 2014, $118,28189-28195$.

98. Mohammadbeigi, F.; Kumar, E. S.; Alagha, S.; Anderson, I.; Watkins, S. P. Carbon Related Donor Bound Exciton Transitions in ZnO Nanowires. J. Appl. Phys. 2014, 116, 053516.

99. Kaschner, A.; Haboeck, U.; Strassburg, M.; Strassburg, M.; Kaczmarczyk, G.; Hoffmann, A.; Thomsen, C. Nitrogen-Related Local Vibrational Modes in ZnO : N. Appl. Phys. Lett. 2002, 80, 19091911.

100. Li, X. N.; Keyes, B.; Asher, S.; Zhang, S. B.; Wei, S. H.; Coutts, T. J.; Limpijumnong, S.; Van de Walle, C. G. Hydrogen Passivation Effect in Nitrogen-Doped ZnO Thin Films. Appl. Phys. Lett. 2005, 86, 122107.

101. Jokela, S. J.; McCluskey, M. D. Unambiguous Identification of Nitrogen-Hydrogen Complexes in ZnO. Phys. Rev. B 2007, 76, 193201.

102. Jokela, S. J.; McCluskey, M. D. Structure and Stability of N-H Complexes in Single-Crystal ZnO. J. Appl. Phys. 2010, 107, 113536.

103. Lavrov, E. V.; Borrnert, F.; Weber, J. Dominant Hydrogen-Oxygen Complex in Hydrothermally Grown ZnO. Phys. Rev. B 2005, 71, 035205.

104. Reynolds, J. G.; Reynolds, C. L.; Mohanta, A.; Muth, J. F.; Rowe, J. E.; Everitt, H. O.; Aspnes, D. E. Shallow Acceptor Complexes in P-Type ZnO. Appl. Phys. Lett. 2013, 102, 152114.

105. Lavrov, E. V. Infrared Absorption Spectroscopy of Hydrogen-Related Defects in ZnO. Physica B 2003, 340, 195-200. 


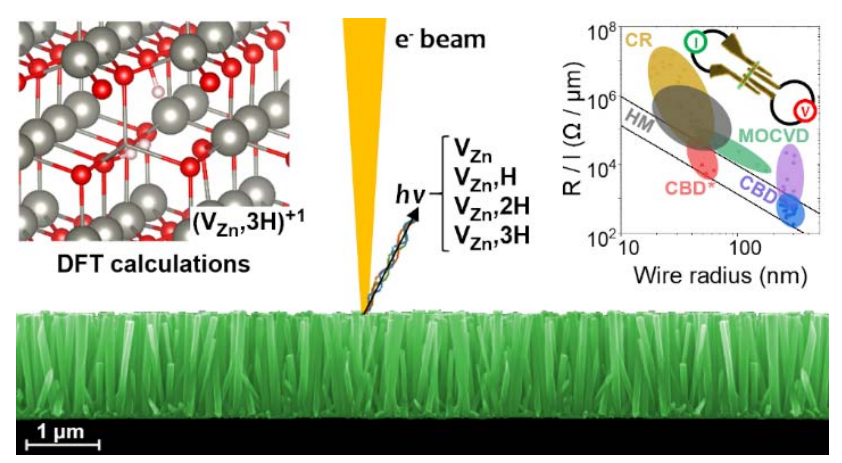

TOC Graphic 